\title{
Benzodiazepine drugs in general medical patients
}

\author{
C M KESSON, J M B GRAY, D H LAWSON
}

British Medical fournal, 1976, 1, 680-682

\section{Summary}

Data from a hospital-based drug surveillance programme were used to determine how often benzodiazepine drugs were used in general medical wards. Benzodiazepines were the drugs most commonly used as hypnotics and were given to $32 \%$ of these patients. Concomitant use of more than one benzodiazepine drug or of benzodiazepines with other psychoactive drugs was common and often irrational. A series of double-blind patient-preference studies comparing various benzodiazepines and a benzodiazepine with an antihistamine showed that for short-term hypnotic effect there were no differences between three common benzodiazepines but elderly patients preferred benzodiazepines to the antihistamine, which produced more undesired effects. These results suggest that currently diazepam is the hypnotic of choice for medical ward inpatients.

\section{Introduction}

Recently the benzodiazepines have superseded barbiturates as hypnotics of choice because of their greater efficacy and safety. ${ }^{12}$ Many benzodiazepines are currently available and their relative efficacy usually unknown. We investigated their use in the medical division of Glasgow Royal Infirmary and describe here a trial designed to establish their relative potency in the management of insomnia.

\section{Methods}

The use of several hypnotics in Glasgow Royal Infirmary during 1970-4 was determined from data provided by the pharmacy. During 1972-3 a drug surveillance programme was operated within the medical division of this hospital. Records were kept of all drugs administered to patients in the division together with details of the patients' age, sex, and diagnoses. For the present study the frequency of hypnotic drug use was ascertained and details of the prescriptions analysed.

A double-blind randomised trial was then set up to compare the relative efficacy of three benzodiazepine hypnotics: flurazepam $(30 \mathrm{mg})$, nitrazepam $(5 \mathrm{mg})$, and diazepam $(5 \mathrm{mg})$; an antihistamine (promethazine $25 \mathrm{mg}$ ); and a placebo, the methods used being similar to those described by Thomson ${ }^{3}$ and Jick et al. ${ }^{4}$ The patients studied were consecutive admissions to medical wards who were conscious, able to communicate a preference to the investigators, and not suffering primarily from hepatic or respiratory insufficiency. None had been previously habituated to hypnotics. All gave their informed consent. The drugs were administered in identical capsules in random order. Five studies were performed comparing each of the drugs with the other. After two nights in hospital patients received one of the drugs on day 3 and the other on day 4. Each drug was given first as often as the other in all comparative groups. On the fifth day their preference was recorded and a record kept of any adverse reactions. In each comparison a limit of 30 preferences was set. Analyses were performed

Medical Division, Royal Infirmary, Glasgow G4 OSF

C M KESSON, MB, MRCP, registrar

J M B GRAY, $\mathrm{MB}$, $\mathrm{CHB}$, research assistant

D H LAWSON, MD, FRCPED, consultant physician sequentially. ${ }^{4-6}$ Preference lines were drawn such that line $\mathrm{A}$ was crossed when the ratio of preference for drug A over drug B was 2:1 and line $B$ was crossed when the preference ratio was $1: 1$. Line $C$ was crossed if neither preference line could be crossed within the total number of patients available when the error limits were set at $5 \%$ (see fig 2).

\section{Results}

HOSPITAL USE OF SELECTED PSYCHOACTIVE DRUGS

The number of tablets of six index psychoactive drugs purchased annually in Glasgow Royal Infirmary are shown in fig 1 . There was a dramatic increase in the use of the two benzodiazepine drugs nitrazepam and diazepam, which was also far greater than the decrease in the use of the other index drugs.

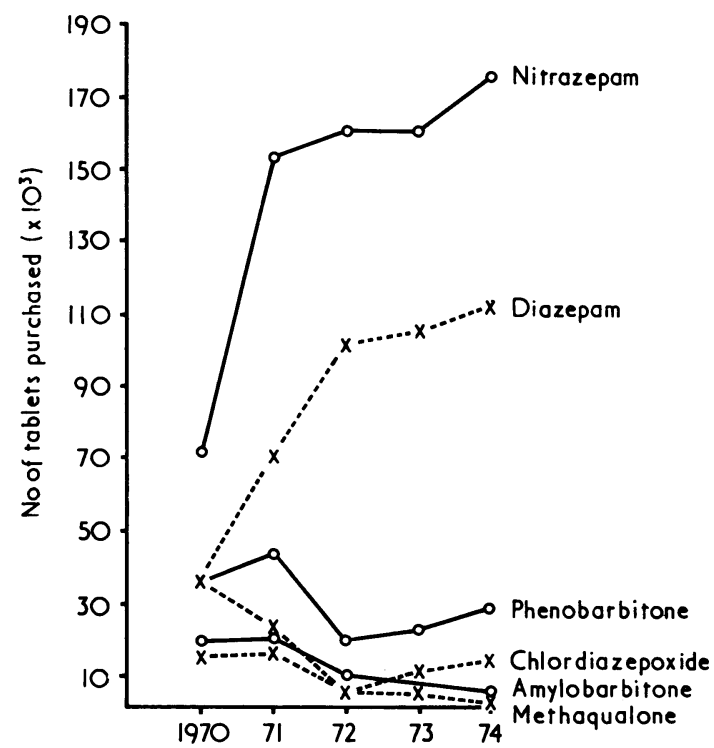

FIG 1-Numbers of tablets of six types of psychoactive drugs purchased annually for Glasgow Royal Infirmary.

\section{DRUG SURVEILLANCE STUDY}

A total of 5288 patients were admitted on one or more occasion during the study. On average the patients were in hospital for 12 days and received 4.6 drugs per admission. The relative frequencies of use of the various hypnotic drugs are shown in the table. Thirty-two per cent of patients (1689) received a benzodiazepine drug. Nitrazepam was used mainly as a hypnotic, whereas diazepam was used mainly as an ariti-anxiety agent.

Nitrazepam-Altogether 1113 patients $(21 \%)$ received oral nitrazepam, the commonest daily dose being $10 \mathrm{mg}$. Of these $260(23 \%)$ also received diazepam, and $169(15 \%)$ received another hypnotic or anxiolytic agent. Of those who also received diazepam most received the drugs concomitantly, whereas consecutive use of nitrazepam and other hypnotics was the rule. About half those receiving nitrazepam and another hypnotic received the former first and half received the latter first. The reasons for the change were infrequently stated in the case records.

Diazepam-Altogether 836 patients $(16 \%)$ received diazepam during the study, $535(64 \%)$ receiving it by mouth. Of those 101 $(19 \%)$ received daily doses up to $5 \mathrm{mg}, 375(70 \%)$ doses of $6-15 \mathrm{mg}$, and $60(11 \%)$ doses exceeding $15 \mathrm{mg}$. Two hundred and fourteen $(41 \%)$ also received nitrazepam, usually at the same time as the diazepam, the former being prescribed as an anti-anxiety agent and 
Common psychoactive drugs prescribed for 5288 medical inpatients. Percentages are of total number of patients admitted

\begin{tabular}{|c|c|c|c|c|c|c|c|}
\hline Drug & Nitrazepam & Diazepam & $\begin{array}{c}\text { Amylobarbitone } \\
\text { sodium }\end{array}$ & $\begin{array}{c}\text { Chloral hydrate } \\
\text { derivatives }\end{array}$ & Amitriptyline & Mandrax* & Others \\
\hline No $(\%)$ & $1113(21)$ & $836(16)$ & $230(4 \cdot 4)$ & $126(2 \cdot 4)$ & $61(1 \cdot 2)$ & $33(0 \cdot 6)$ & $45(0.9)$ \\
\hline
\end{tabular}

* Mixture of methaqualone $250 \mathrm{mg}$ and diphenhydramine $25 \mathrm{mg}$.

the latter as an hypnotic. In addition, 106 diazepam recipients $(20 \%)$ also received another hypnotic or anti-anxiety agent together with the diazepam. A further 46 patients $(9 \%)$ received oral diazepam, oral nitrazepam, and another oral hypnotic during their admission. Thus 366 of 535 oral diazepam recipients $(68 \%)$ received another hypnotic or anxiolytic drug during their admission.

\section{PATIENT PREFERENCE STUDIES}

A total of 107 patients were admitted to the first part of the patient preference study, $65(60 \%)$ of whom were men. Their mean age was 52 years, mean admission blood urea $5.4 \mathrm{mmol} / 1(33 \mathrm{mg} / 100 \mathrm{ml})$ and their mean packed cell volume $40 \%$

Flurazepam $(30 \mathrm{mg})$ v placebo-This study showed a statistically significant result at the $5 \%$ level in favour of flurazepam in a $2: 1$ ratio over placebo after 23 patients had been studied (fig 2 ). Three patients could not state a preference for either drug, having slept equally well on both occasions.

Flurazepam (30 mg) $v$ nitrazepam $(5 \mathrm{mg})$-Twenty-two patients participated in this study, and six could not state a preference for either drug. The study was stopped when line $C$ was crossed, indicating a failure to show superiority of one drug over the other within the study limits (fig 2)

Nitrazepam $(5 \mathrm{mg}) v$ diazepam $(5 \mathrm{mg})$-Twenty-eight patients participated in this study, and 10 failed to state a preference for either drug. The study failed to show significant superiority of nitrazepam over diazepam at the prescribed doses: 10 patients preferred nitrazepam and eight preferred diazepam.

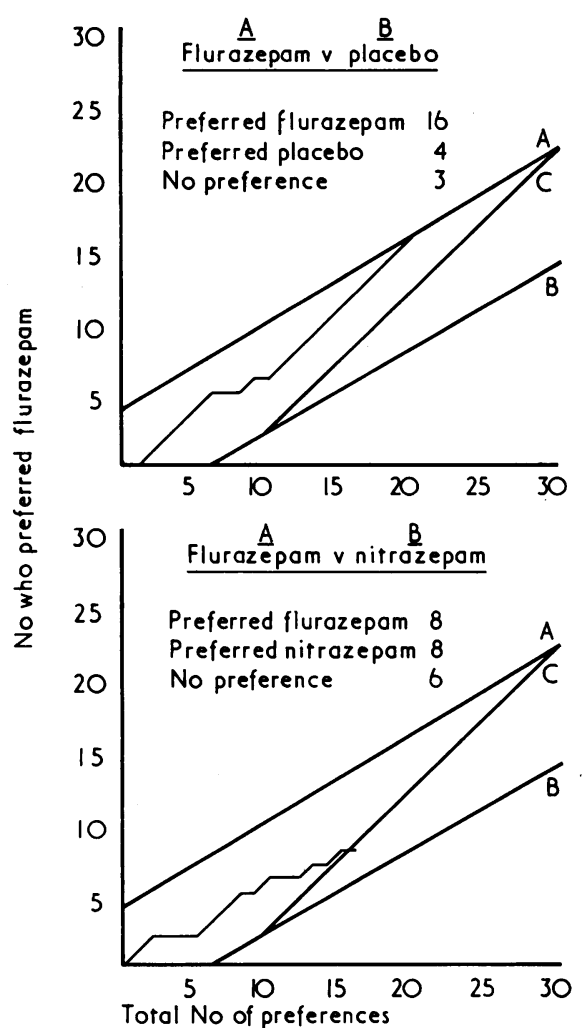

FIG 2-Results in flurazepam $v$ placebo study and flurazepam $v$ nitrazepam study. Top diagram shows that line $A$ was crossed, indicating that the ratio of preference for drug $A$ over drug $B$ was $2: 1$. Bottom diagram shows that line $C$ was crossed, indicating that neither A nor B could be crossed within limits of numbers of patients available and so neither drug was significantly better than the other.
Promethazine $(25 \mathrm{mg}) v$ flurazepam $(30 \mathrm{mg})$-Fourteen patients took part in this study and only one failed to state a preference. There was a statistically significant result at the $5 \%$ level in favour of promethazine (preferred by 12 patients) in a 2-1 ratio over flurazepam (preferred by one).

Nitrazepam $(5 \mathrm{mg}) v$ promethazine $(25 \mathrm{mg}$ )-Twenty patients participated in this study, and three failed to state a preference for either drug. The study failed to show any superiority of nitrazepam over promethazine at the doses given: nine patients preferred nitrazepam and eight preferred promethazine.

In view of the apparent conflict between the above studies the data were scrutinised for possible confounding factors. There was a trend towards a preference for drugs given on the first day of the study over those given on the second day in a ratio of $4: 3$. Nevertheless, this did not explain the observed differences. In all five studies the distributions of admission blood urea concentrations, packed cell volumes, and discharge diagnosis categories were similar. There were variations in the proportion of men to women between the study groups, but these did not explain the differences. When the age of the patients was analysed it was noted that the youngest patients had, by chance, congregated in the promethazine-flurazepam study. Moreover, when the patient preferences in the nitrazepam-promethazine comparison were analysed by age we found that younger patients preferred promethazine whereas older ones preferred nitrazepam. This hypothesis was therefore tested in a further two studies in which nitrazepam $(5 \mathrm{mg})$ and promethazine $(25 \mathrm{mg})$ were compared separately in two groups of young and old patients who were otherwise similar to each other and to the population originally studied.

Older patients-Twenty-seven patients over 64 years (average age 71) were given nitrazepam $(5 \mathrm{mg})$ and promethazine $(25 \mathrm{mg})$. There was a statistically significant result at the $5 \%$ level in favour of nitrazepam in a 2:1 ratio over promethazine. Although six patients showed no preference, 17 preferred nitrazepam and only four preferred promethazine.

Younger patients-Twenty patients under 45 years (average age 34) were given nitrazepam $(5 \mathrm{mg})$ and promethazine $(25 \mathrm{mg})$. The study was stopped because the 2:1 preference line for nitrazepam could not be reached within 30 patient preferences. Five patients preferred neither, seven preferred nitrazepam, and eight preferred promethazine.

\section{ADVERSE REACTIONS}

The overall adverse reaction rate in the first series of studies was $22 \%$ (24 out of 107 patients), varying from eight of the 34 patients $(24 \%)$ given promethazine to one of the 28 patients $(4 \%)$ receiving diazepam. Of the other benzodiazepines, flurazepam had fewest reported side effects (4 out of 59: 7\%) and nitrazepam had the greatest proportion (10 out of $70: 14 \%$ ). The predominant reaction with both drugs was hangover.

Similar adverse reactions were reported by the patients participating in the second series of studies: 17 out of 47 promethazine recipients $(36 \%)$ experienced an adverse effect compared with five out of 47 nitrazepam recipients $(11 \%)$. The frequencies of adverse reactions were similar in young and old patients.

\section{Discussion}

Our findings emphasise the extent to which the benzodiazepines are now used in hospital medical practice and also show that different members of this class of drug are often prescribed for different indications in the same patient on the same day. The commonest drugs so prescribed are diazepam, used as an anti-anxiety agent, and nitrazepam, used as a hypnotic. Despite this habit our findings confirm the report of Greenblatt and Shader ${ }^{1}$ that there is no evidence to suggest differences in the hypnotic properties of these drugs when given on a short- 
term basis to medical inpatients. Since there is no pharmacological evidence to support the current practice of using two different benzodiazepines together, and a potential reduction in cost to the Health Service of changing the practice, we undertook a randomised double-blind patient-preference study to test the hypothesis that one of the three commonly used benzodiazepines (flurazepam, nitrazepam, and diazepam) was better than the others as a short-term hypnotic in medical inpatients.

This study design was chosen because of simplicity, economy in staff time, minimum patient interference, use of each patient as his own control, and the benefits of a sequential analysis design. Such trial methods have been shown to be reproducible and reliable in assessing symptomatic drug treatment qualitatively provided only that the basic symptoms under treatment do not vary on a daily basis. ${ }^{3}$ Variability of symptoms in patientpreference studies are of considerable significance and may invalidate the use of this technique. ${ }^{7}$ Nevertheless, this did not constitute a significant problem in our study, and Zelvelder, ${ }^{8}$ in an extensive review of the techniques of evaluating hypnotics, recommended this approach as the most efficient one available for evaluating short-term hypnotic efficacy. Our studies confirmed that the benzodiazepines are effective hypnotics ${ }^{9}$ and failed to show a clinically significant difference in efficacy between them when used in this setting. Despite the relatively small numbers of patients, the incidence of undesired effects (usually excessive sedation) seemed to be higher with nitrazepam than with diazepam or flurazepam. Our data also show that older patients admitted to medical wards have a significant preference for a benzodiazepine as a hypnotic rather than an antihistamine.

This work was supported by a generous grant from the Scottish Home and Health Department and by Roche Products Ltd. Data from the pharmacy department, Glasgow Royal Infirmary, were kindly provided by Miss J Fleming.

Requests for reprints should be addressed to $\mathrm{Dr} C \mathrm{M}$ Kesson.

\section{References}

1 Greenblatt, D J, and Shader, R I, Benzodiazepines in Clinical Practice. New York, Raven Press, 1974

2 Barraclough, B M, Lancet, 1974, 1, 57

3 Thomson, T J, British Medical fournal, 1958, 2, 1140.

${ }^{4} \mathrm{Jick}, \mathrm{H}$, et al, New England fournal of Medicine, 1966, 275, 1399.

5 Snell, E S, and Armitage, P, Lancet, 1957, 1, 860.

6 Parsons, T W, and Thomson, T J, British Medical fournal, 1961, 1, 171

Huskisson, E C, and Grayson, M F, British fournal of Clinical Pharmacology, 1974, 1, 151.

${ }^{8}$ Zelvelder, W G, Therapeutic Evaluation of Hypnotics. London, Heinemann, 1971.

9 Kales, A, and Scharf, M B, The Benzodiazepines. New York, Raven Press, 1973.

\title{
Spironolactone in essential hypertension: evidence against its effect through mineralocorticoid antagonism
}

\author{
B I HOFFBRAND, C J EDMONDS, T SMITH
}

British Medical fournal, 1976, 1, 682-684

\begin{abstract}
Summary
The effect of a six-week course of spironolactone $300 \mathrm{mg} /$ day was examined in 25 unselected patients with essential hypertension. In the blood spironolactone produced a significant rise in urea and potassium concentrations and a fall in sodium and bicarbonate concentrations. In six patients blood pressure was normal at the end of the course, while in five patients there was almost no change. Studies of the effects of spironolactone on various indices usually affected by mineralocorticoids-namely, blood electrolytes, total body potassium, and rectal electrical properties-showed no differences between responding and non-responding patients. Mineralocorticoid excess therefore seems to be rarely responsible for essential hypertension and the influence of spironolactone cannot at present be fully explained.
\end{abstract}

\section{Introduction}

Spironolactone has been known for many years to have hypotensive properties. In primary hyperaldosteronism it rapidly

Whittington Hospital, Archway Road, London N19 5NF

B I HOFFBRAND, MD, MRCP, consultant physician

Clinical Research Centre, Harrow, Middlesex HA1 3UJ

C J EDMONDS, MD, FRCP, consultant physician and member of MRC scientific staff

T SMITH, BSC, PHD, physicist and member of MRC scientific staff corrects the biochemical abnormalities and usually restores the blood pressure to normal. ${ }^{1}$ In essential hypertension spironolactone in a daily dose of about $100 \mathrm{mg}$ has a hypotensive effect about the same as that of the thiazide diuretics. ${ }^{3}$ Several workers have shown that in essential hypertension spironolactone is especially effective among patients with subnormal blood renin levels (low renin hypertension), ${ }^{4-6}$ which suggests that low renin hypertension may be due to increased mineralocorticoid activity. Conversely, it has been argued that patients with essential hypertension who respond to spironolactone are likely to have mineralocarticoid excess. ${ }^{7}$ Such mineralocorticoid excess has, however, only rarely been shown in hypertensive patients. An alternative suggestion ${ }^{8}$ is that aldosterone itself is responsible since although the blood levels are within the normal range they may, nevertheless, be inappropriately high for the blood renin concentrations. Our object was to investigate a group of untreated patients with essential hypertension to examine the effect of spironolactone on blood pressure and some biological indices of mineralocorticoid activity to determine whether there was any difference between those patients whose blood pressure responded to spironolactone and those whose blood pressure did not respond. The transepithelial electrical potential difference of rectal mucosa rises considerably when stimulated by aldosterone and other mineralocorticoids, ${ }^{9-13}$ reflecting the increase of sodium transport, and we used this as one of the indices of mineralocorticoid activity.

\section{Methods}

Studies were done on 25 untreated outpatients ( 14 men, 11 women) whose supine diastolic blood pressures were over $100 \mathrm{~mm} \mathrm{Hg}$ on at least three occasions. A preliminary observation period of at least four weeks preceded the administration of spironolactone. The mean age 